\title{
«Alles im Griff?»
}

Da alkoholische Getränke nicht nur Sucht- sondern auch Genussmittel sind, bestehen vielfach Hemmungen, dieses Konsumverhalten anzusprechen. Und doch wissen viele nicht, wo die Grenzen zwischen Genuss und Abusus zu ziehen sind!

Der vor einem Jahr lancierte Gesprächs-Leitfaden war vom gesamtschweizerischen Alkoholpräventionsprogramm "Alles im Griff?» erarbeitet und versandt worden. Die Auswertung des Aussands liegt nun vor und wird nachstehend in zusammengefasster Form publiziert. Die vorliegenden Ergebnisse zeigen klar, dass wir Ärztinnen und Ärzte eine wichtige Rolle bei der Früherfassung zu spielen haben und dass die Fortbildung auf diesem Gebiet vorangetrieben werden soll. Dem Editorial in dieser Nummer können Sie entnehmen, dass bereits ein Kursprogramm vorliegt - erfahrungsgemäss ereignet sich für interessierte Kolleginnen und Kollegen durch den Anteil Selbsterfahrung mehr als bei alleiniger Lektüre -, doch auch ein Manual, in Zusammenarbeit mit dem Ressort Prävention und Public Health der FMH konzipiert, ist schon weit gediehen und wird in der Schweizerischen Ärztezeitung nach seiner Fertigstellung angezeigt.

Dr. Ursula Steiner-König Vizepräsidentin der FMH, Ressort Prävention

\section{"Ça débouche sur quoi?»}

Etant donné que les boissons alcoolisées ne font pas qu'engendrer la dépendance, mais sont également des produits d'agrément, il est souvent difficile d'aborder la question de la consommation. En outre, bon nombre de personnes ne savent pas où fixer la limite entre plaisir et abus!

Il y a un an, un guide a été élaboré et envoyé dans le cadre du programme de prévention national contre l'alcoolisme «Ça débouche sur quoi?». L'évaluation de cet envoi est maintenant terminée et le résultat est publié ci-après sous forme de résumé. Les résultats présentés illustrent clairement que nous autres médecins sommes appelés à jouer un rôle important en matière de prévention et que la formation continue dans ce domaine doit être encouragée. Or, comme vous l'aurez lu dans l'éditorial du présent numéro, un programme de cours a été mis sur pied - d'après ce que nous savons, l'expérience compte plus que la lecture seule - et un manuel est actuellement mis au point, en collaboration avec le département de prévention et santé publique de la FMH. La parution de ce manuel sera annoncée dans le Bulletin des médecins suisses de la FMH. 